\title{
Perbandingan Algoritma Nazief \& Adriani Dengan Algoritma Idris Untuk Pencarian Kata Dasar
}

\author{
Adhi Prasidhatama $^{[1]}$, Kristien Margi Suryaningrum ${ }^{[2]}$ \\ Teknik Informatika, Fakultas Teknik dan Desain, Universitas Bunda Mulia \\ email: aprasidatama@gmail.com \\ Teknik Informatika, Fakultas Teknik dan Desain, Universitas Bunda Mulia \\ email: ksuryaningrum@bundamulia.ac.id
}

\begin{abstract}
Stemming is a process used to search root words. Stemming can be implemented as preprocessing in text processing. There are many stemming algorithms, one of them is Nazief \& Adriani and Idris. Nazief \& Adriani algorithm is an algorithm created by Bobby Nazief and Mirna Adriani to find the root word of Bahasa Indonesia. While the Idris algorithm is an algorithm created by Norisma Idris to find the root words of Malay language. Indonesian and Malay have similar language styles, so researchers want to find out whether the Idris algorithm can be used as one of the Indonesian stemming algorithms. To know which algorithm is better, then in this research will be explained about process speed and accuracy of result of each of those algorithm. After knowing the result of comparison of stemming algorithm, hopefully can help you in choosing which algorithm will be used for find root word of Bahasa Indonesia.

Keywords: Perbandingan, Nazief \& Adriani, Idris, Stemming
\end{abstract}

\section{PENDAhuluan}

Komunikasi merupakan suatu proses dimana seseorang atau beberapa orang menciptakan dan menggunakan informasi agar terhubung dengan lingkungan dan orang lain. Komunikasi pada umumnya dilakukan secara lisan atau verbal yang dapat dimengerti oleh kedua belah pihak. Dengan adanya teknologi kita dapat berkomunikasi dengan satu dan lainnya dengan mudah. Namun tanpa disadari bahwa berkomunikasi langsung dengan sebuah program masih dianggap sulit. Dikarenakan oleh perbedaan bahasa maupun tatanan bahasanya itu sendiri. Sehingga program tidak dapat dengan mudah mengerti dari apa yang dimaksudkan oleh manusia.

Untuk mengerti apa yang dimaksud oleh manusia sebuah program harus memiliki beberapa kemampuan seperti text preprocessing, ekstraksi fitur, pencarian kata dasar, hingga pelatihan atau pembelajaran untuk mengembangkan pola pikirnya. Stemming merupakan suatu proses untuk menemukan kata dasar dari sebuah kata dengan menghilangkan semua imbuhan (affixes) baik yang terdiri dari awalan (prefixes), sisipan (infixes), akhiran (suffixes) dan kombinasi dari awalan dan akhiran (confixes) pada kata turunan. Stemming adalah inti dari teknik pemrosesan natural language untuk mendapatkan informasi kembali (Information Retrieval) yang efektif dan efesien dan secara luas dapat diterima oleh pengguna (users). Stemming digunakan untuk mengganti bentuk dari suatu kata menjadi kata dasar dari kata tersebut yang sesuai dengan struktur morfologi bahasa Indonesia yang baik dan benar. Pada pencarian kata dasar (stemming) khususnya bahasa Indonesia terdapat beberapa algoritma seperti Jelita Asian tahun 2005, Arifin \&
Setiono tahun 2002, Nazief \& Adriani tahun 1996, Ahmad Yusoff Sembok tahun 1996, Vega tahun 2001, Idris tahun 2001 dan Enhanced Confix Stripping Stemmer tahun 2008.

Mengetahui ada berbagai macam algoritma untuk stemming bahasa Indonesia. Penulis memutuskan untuk mempersempit ruang penelitian ke algoritma Nazief \& Adriani dan algoritma Idris. Dikarenakan algoritma Nazief \& Adriani merupakan algoritma stemming yang populer untuk memproses teks berbahasa Indonesia, sedangkan algoritma Idris sendiri kurang populer untuk stemming bahasa Indonesia. Maka dari itu penilitian ini berjudul "Analisis Perbandingan Algoritma Nazief \& Adriani dengan Algoritma Idris untuk Pencarian Kata Dasar pada Teks Bahasa Indonesia Berbasis Website". Pada penelitian ini akan membahas mengenai cara kerja, kelebihan \& kekurangan, hingga hasil dari tiap algoritma yang akan dibandingkan.

\section{Information retrievals System}

Information retrievals System atau sistem temu balik informasi merupakan bagian dari computer science tentang pengambilan informasi dari dokumendokumen yang didasarkan pada isi dan konteks dari dokumen-dokumen itu sendiri.[1] Informasi yang diambil dapat berupa teks, gambar, audio, dan video yang berguna untuk melakukan penyimpanan, pencarian, dan pemeliharaan informasi.

\section{Text preprocessing}

Text preprocessing berfungsi mengubah data tekstual yang tidak terstruktur ke dalam data terstruktur dan disimpan dalam basis data. Tahap 
preprocessing terdiri dari beberapa langkah yaitu : case floding, tokenization, filtering dan stemming. [5]

Pada proses case floding karakter selain huruf dihilangkan dan semua huruf diubah menjadi lowercase. Tokenization adalah proses dimana sebuah kalimat dipotong untuk menghasilkan kata-kata yang akan digunakan untuk proses selanjutnya. Pengambilan kata-kata penting dari hasil tokenization merupakan proses yang dilakukan dalam filtering. Proses filtering memiliki dua teknik yaitu stop list (membuang kata yang kurang penting) dan word list (menyimpan kata yang penting). Setelah mendapatkan kata-kata yang dirasa penting, selanjutnya dilakukan proses stemming. Proses pada tahap stemming ialah melakukan pengolahan dan pencarian kata dasar dari hasil filtering atau sekumpulan kata-kata yang sudah dianggap penting.

\section{Algoritma Stemming Nazief \& Adriani}

Algoritma yang dibuat oleh Bobby Nazief dan Mirna Adriani memiliki tahapan sebagai berikut.[2]

1. Cari kata yang akan distem dalam kamus. Jika ditemukan maka diasumsikan bahwa kata tesebut adalah kata dasar. Maka algoritma berhenti.

2. Infleksi akhiran ("-lah", “-kah", “-ku”, “-mu”, atau "-nya") dibuang. Jika berupa partikel ("“lah", “-kah", "-tah" atau "-pun”) maka langkah ini diulangi lagi untuk menghapus kata ganti posesif ("-ku”, “-mu”, atau "-nya"), jika ada.

3. Hapus penurunan akhiran ("-i", "-an" atau "kan"). Jika kata ditemukan di kamus, maka algoritma berhenti. Jika tidak maka ke langkah 3a.

a. Jika "-an" telah dihapus dan huruf terakhir dari kata tersebut adalah "-k", maka "-k" juga ikut dihapus. Jika kata tersebut ditemukan dalam kamus maka algoritma berhenti. Jika tidak ditemukan maka lakukan langkah $3 b$.

b. Akhiran yang dihapus (“-i", “-an” atau “kan”) dikembalikan, lanjut ke langkah 4.

4. Hapus penurunan awalan. Jika pada langkah 3 ada akhiran yang dihapus maka pergi ke langkah $4 \mathrm{a}$, jika tidak pergi ke langkah $4 \mathrm{~b}$.

a. Periksa tabel kombinasi awalan akhiran yang tidak diizinkan. Jika ditemukan maka algoritma berhenti, jika tidak pergi ke langkah 4b.

b. Pada langkah ini dilakukan perulangan sebanyak tiga kali. Tentukan tipe awalan kemudian hapus awalan. Jika kata dasar belum juga ditemukan lakukan langkah 5, jika sudah maka algoritma berhenti. Catatan: jika awalan kedua sama dengan awalan pertama algoritma berhenti.

5. Melakukan Recoding.
6. Jika semua langkah telah selesai tetapi tidak juga berhasil maka kata awal diasumsikan sebagai kata dasar lalu proses diakhiri.

\section{Algoritma Stemming Idris}

Berikut tahapan-tahapan mengenai stemming menggunakan algoritma Idris adalah sebagai berikut.[4]

1. a. Kata yang belum di-stemming dicari pada kamus umum atau Kamus Besar Bahasa Indonesia (KBBI). Jika kata itu langsung ditemukan, berarti kata tersebut adalah kata dasar. Kata tersebut dikembalikan dan algoritma dihentikan.

b. Kata yang belum di-stemming dicari pada kamus lokal. Jika kata itu langsung ditemukan, berarti kata tersebut adalah kata dasar. Kata tersebut dikembalikan dan algoritma dihentikan. Kamus lokal digunakan karena algoritma Idris dibuat untuk stemming bahasa melayu, yang dimana kamus lokal berisi kata-kata dasar bahasa melayu. Sedangkan stemming bahasa Indonesia tidak memerlukan kamus lokal.

2. Menghilangkan turunan awalan. Langkah ini terus dilakukan sampai tidak ada lagi turunan awalan. Jika tidak ada lagi, maka lanjutkan ke langkah berikutnya. Untuk beberapa kombinasi imbuhan, dilakuan penghilangan awalan terlebih dahulu. Yaitu pada kombinasi imbuhan "berlah", "ber-an", "men-i", "di-i", "pe-i", "ter-i”.

3. Hilangkan ifleksi akhiran terlebih dahulu. Jika hal ini berhasil dan akhiran adalah partikel ("“lah", "-pun" dan "-kah"), langkah ini dilakukan lagi untuk menghilangkan kata ganti akhiran posesif ("ku", "mu" atau "nya").

4. Hilangkan turunan akhiran. Langkah ini terus dilakukan sampai tidak ada lagi penurunan akhiran. Jika tidak ada lagi, maka lanjutkan ke langkah berikutnya.

5. Setelah setiap penghilangan imbuhan dilakukan, maka lakukan pengecekan menggunakan kamus. Jika kata ditemukan, maka algoritma berhenti dan tidak perlu dilakukan pengecekan terhadap imbuhan lainnya. Jika sampai selesai penghilangan imbuhan masih belum menemukan kata dasar, maka dilakukan recoding.

6. Jika semua langkah sudah dilakukan termasuk recoding dan tidak juga ditemukan dalam kamus, maka algoritma ini akan manganggap kata semula sebagai kata dasar.

\section{METODE PENELITIAN}

Metode pengembangan sistem yang digunakan adalah model watefall. Berikut merupakan jabaran mengenai metode pengembangan sistem model waterfall.[3]

1. Analisis Kebutuhan

Dalam tahapan ini penulis menentukan kebutuhan-kebutuhan pada sistem Analisa 
Perbandingan Algoritma Nazief \& Adriani dengan Algoritma Idris untuk Pencarian Kata Dasar pada Teks Bahasa Indonesia Berbasis Website baik itu kebutuhan fungsional maupun kebutuhan non fungsional.

\section{Desain Sistem}

Dalam tahapan desain sistem ini, penulis membuat perancangan dari model atau desain sistem dengan menggunakan beberapa alat bantu untuk menggambarkan sistem berjalan ataupun sistem baru yang akan dikembangkan secara logika. Untuk rincian prosedur menggunakan flowchart sedangkan untuk menggambarkan susunan logis antar data dan hubungannya dengan sistem penulis menggunakan Entity Relationship Diagram (ERD).

3. Implementasi dan Pengujian Unit

Pada tahap ini, penulis melakukan penerjemahan desain yang telah dibuat ke dalam bentuk software yang dirancang dengan bahasa pemrograman PHP dan basis data menggunakan MySQL. Selanjutnya melakukan pengujian terhadap program yang dibangun per unit atau per modul kerja. Dimana semua fungsi-fungsi software tersebut diuji cobakan, agar software bebas dari error dan hasilnya harus benar-benar sesuai dengan kebutuhan yang sudah didefinisikan sebelumnya.

4. Pengujian Sistem

Pada tahap ini program yang telah dibuat dan diuji tiap unitnya kemudian disatukan menjadi suatu sistem dan diuji secara keseluruhan berguna untuk menguji tingkat integrasi antar unit yang dibuat sebelumnya.

\section{Maintenance atau Perawatan}

Pada tahap ini program akan diawasi kinerja dan hasil keluarannya. Jika terjadi sebuah kesalahan pada saat program beoperasi atau hasil keluaran tidak sesuai dengan yang diharapkan, maka akan dilakukan perawatan yang berguna untuk memperbaiki program.

\section{HASIL DAN PEMBAHASAN}

Objek pengujian untuk mengetahui kecepatan proses dan akurasi dari algoritma Nazief \& Adriani dan Idris adalah berupa wacana berupa teks. Berikut merupakan tampilan dari laman masukkan pengujian dengan wacana berjudul "Legenda Danau Toba" dengan jumlah kata 520.

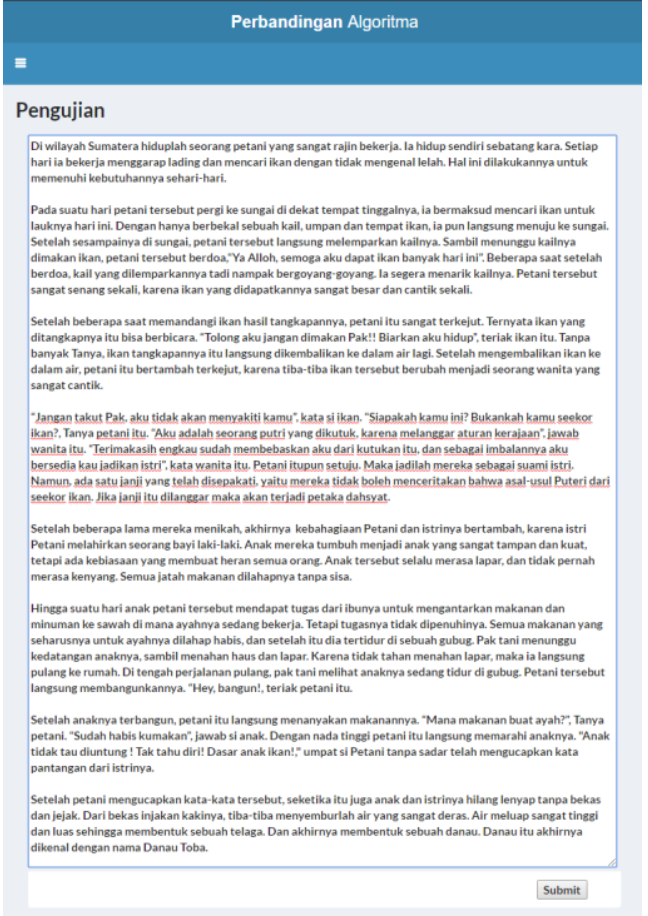

Gambar 1. Laman masukkan pengujian

Pada gambar 1 menampilkan bagaimana teks wacana dimasukkan untuk memulai pengujian. Setelah teks wacana selesai di masukkan. Penguji dapat memulai proses pengujian dengan menekan tombol submit.

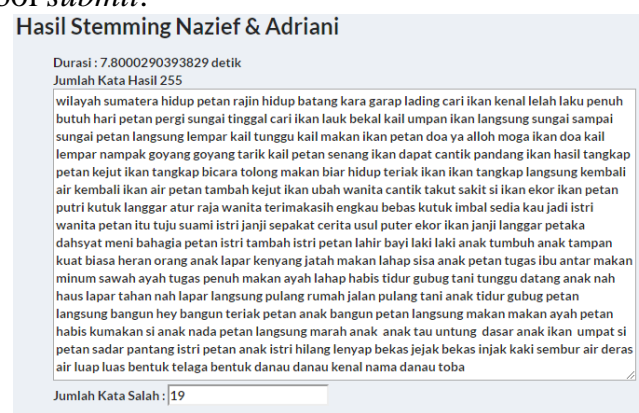

Gambar 2. Hasil stemming Nazief \& Adriani

Pada gambar 2 menampilkan hasil dari pengolahan algoritma Nazief \& Adriani. Atribut yang ditampilkan pada hasil stemming Nazief \& Adriani berupa durasi pemrosesan, jumlah kata yang dihasilkan, data kata dari hasil stemming, dan jumlah kata salah. Jumlah kata salah merupakan jumlah dari kata yang dihasilkan dari stemming namun tidak sesuai dengan kata dasarnya.

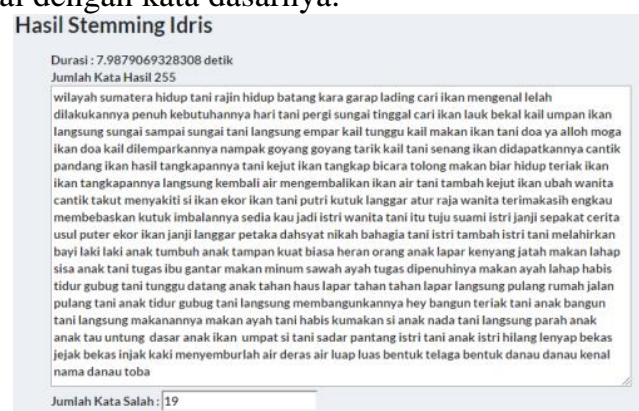

Gambar 3. Hasil stemming Idris 
Pada gambar 3 menampilkan hasil dari pengolahan algoritma Idris. Atribut yang ditampilkan pada hasil stemming Idris berupa durasi pemrosesan, jumlah kata yang dihasilkan, data kata dari hasil stemming, dan jumlah kata salah. Jumlah kata salah merupakan jumlah dari kata yang dihasilkan dari stemming namun tidak sesuai dengan kata dasarnya.

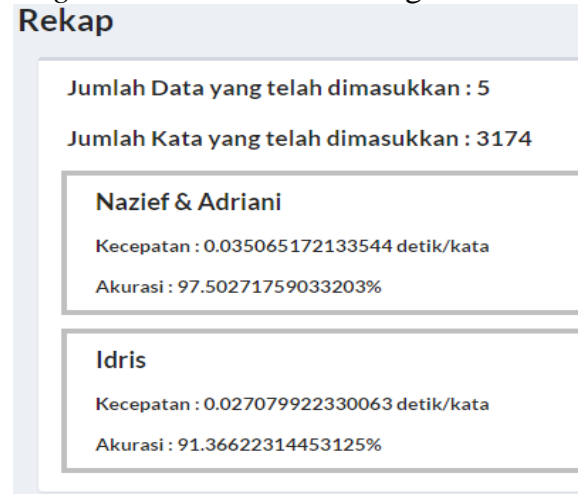

Gambar 4. Laman Rekap hasil Pengujan

Pada gambar 4 menampilkan rekap dari pengujian yang telah dilakukan, seperti jumlah data yang telah dimasukkan, total jumlah kata, hingga kecepatan dan akurasi dari masing-masing algoritma. Kecepatan didapatkan dari membagi jumlah waktu pemrosesan dengan jumlah kata. Sementara akurasi didapatkan dari rata-rata hasil jumlah kata yang benar dibagi dengan jumlah kata yang dimasukkan di awal.

Berikut merupakan hasil pengujian yang telah dilakukan terhadap 5 teks wacana berbeda.

\begin{tabular}{|c|c|c|c|c|c|}
\hline No & $\begin{array}{c}\text { Nama } \\
\text { wacana }\end{array}$ & $\begin{array}{l}\text { Jumla } \\
\text { h kata }\end{array}$ & $\begin{array}{l}\text { Algorit } \\
\text { ma }\end{array}$ & $\begin{array}{l}\text { Waktu } \\
\text { proses } \\
\text { (detik) }\end{array}$ & $\begin{array}{c}\text { Akurasi } \\
(\%)\end{array}$ \\
\hline 1 & $\begin{array}{c}\text { Legenda } \\
\text { Danau } \\
\text { Toba }\end{array}$ & 520 & $\begin{array}{l}\text { Nazief } \\
\& \\
\text { Adrian } \\
i\end{array}$ & 7.80 & 92.55 \\
\hline 2 & $\begin{array}{c}\text { Legenda } \\
\text { Danau } \\
\text { Toba }\end{array}$ & 520 & Idris & 7.99 & 92.55 \\
\hline 3 & $\begin{array}{l}\text { Legenda } \\
\text { Sangkuri } \\
\text { ang }\end{array}$ & 645 & $\begin{array}{l}\text { Nazief } \\
\& \\
\text { Adrian } \\
i\end{array}$ & 15.8 & 97.07 \\
\hline 4 & $\begin{array}{l}\text { Legenda } \\
\text { Sangkuri } \\
\text { ang }\end{array}$ & 645 & Idris & 11.09 & 88.56 \\
\hline 5 & $\begin{array}{c}\text { Cerita } \\
\text { Rakyat } \\
\text { Timun } \\
\text { Mas } \\
\text { Cerita }\end{array}$ & 637 & $\begin{array}{l}\text { Nazief } \\
\& \\
\text { Adrian } \\
i\end{array}$ & 10.98 & 99.1 \\
\hline 6 & $\begin{array}{l}\text { Rakyat } \\
\text { Timun } \\
\text { Mas }\end{array}$ & 637 & Idris & 8.15 & 92.84 \\
\hline 7 & Legenda & 639 & Nazief & 10.27 & 99.68 \\
\hline
\end{tabular}

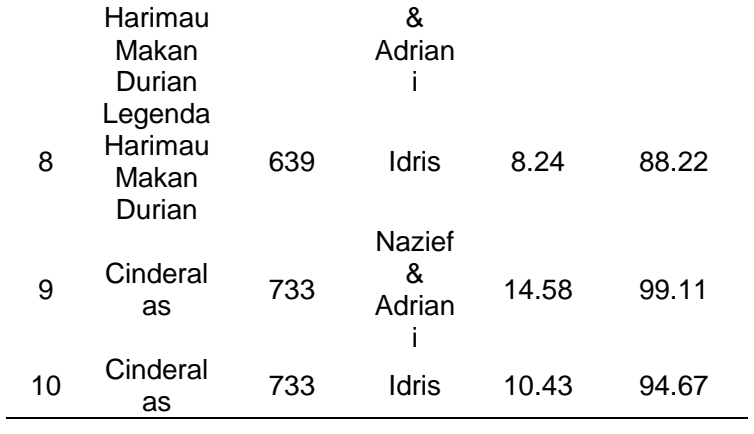

\section{KESIMPULAN}

Setelah dilakukan pengujian, maka diperoleh kesimpulan sebagai berikut:

1. Algoritma stemming Idris memiliki waktu pemrosesan yang lebih cepat dibandingkan dengan algoritma stemming Nazief \& Adriani.

2. Algoritma stemming Nazief \& Adriani memiliki akurasi hasil yang lebih tinggi dibandingkan dengan algoritma stemming Idris.

\section{REFERENSI}

[1] Hasanah, Nur. 2017. Sistem Pencarian Skripsi Berbasis Information Retrieval di FASTIKOM UNSIQ. Jurnal PPKM. 1 (1):105-113.

[2] Nugroho, Hargyo Tri. 2017. Pengaruh Algoritma Stemming Nazief-Adriani Terhadap Kinerja Algoritma Winnowing Untuk Mendeteksi Plagiarisme Bahasa Indonesia. ULTIMA Computing. 9 (1):36-40.

[3] Oktarino, Ade. 2015. Perancangan Sistem Informasi Rekam Medis Pasien pada Klinik Bersalin Kasih Ibu Menggunakan Metode Waterfall. Scientia Journal. 4 (3):239-247.

[4]Permatasari, Nindy. 2016. Analisa Perbandingan Algoritma Idris dan Algoritma Enhanced Confix (ECS) Stemmer Pada Dokumen Teks Bahasa Indonesia. Skripsi. Universitas Komputer Indonesia, Bandung.

[5] Rahmawati, L. 2016. Analisa Clustering Menggunakan Metode K-Means dan Hierarchical Clustering (Studi Kasus: Dokumen Skripsi Jurusan Kimia, Fmipa, Universitas Sebelas Maret). Surakarta: ITSmart: Jurnal Teknologi dan Informasi. Vol. 3, No. 2: 66-73. 